\title{
Students' navigation of the uncharted territories of academic writing
}

Bharuthram, S. and McKenna, S.

\begin{abstract}
Many students enter tertiary education unfamiliar with the 'norms and conventions' of their disciplines. Research into academic literacies has shown that in order to succeed in their studies, students are expected to conform to these norms and conventions, which are often unrecognized or seen as 'common sense' by lecturers. Students have to develop their own 'map' of their programme's expectations in order to make sense of the seemingly mysterious practices they are expected to take on. This study, undertaken at a University of Technology in South Africa, details students' perceptions of their writing difficulties and their attempts to navigate their way through various writing tasks. The findings reveal that students experience a range of difficulties and that the students often feel unsupported in their travails with academic writing.
\end{abstract}

\section{Introduction}

In the South African higher education context, lecturers regularly express a feeling of dissatisfaction with the vast majority of their students' writing. As a result, one of the main aims of academic development programmes in South Africa is to improve students' writing practices through a variety of interventions. However, often these interventions are confined to 'add on' academic development and do not fi into the mainstream curricula and they often fail to take the practices required by that curriculum much into account (see for example McKenna 2004a, Boughey 2007). Many of our students enter tertiary education unfamiliar with the writing norms and conventions of their disciplines and as fi generation university students; they are also often unfamiliar with the expectations of higher education generally (Scott et al. 2007).

In order for these students to acquire the practices required for higher education success, the form and function of the latter need to be made explicit. In a sense, students need to be provided with a map of their discipline's norms. Such mapping out proves difficult for lecturers who may be either unaware of the existence of such norms and conventions or see them as 'common sense'. This article discusses students' attitudes towards writing with the intention of more specifically identifying the writing difficulties students experience in higher education.

\section{Literature Review}

In an understanding of writing as a socially constructed practice, as advocated here, there is a shift away from an understanding of writing as being the production of an autonomous text and there is an awareness of the relevance of the context in which writing takes place. Writing is thus understood as a set of social practices taking place 
within specific contexts. The processes of reading and writing are thus not seen as technical literacy skills but as being intricately entwined with the people doing the reading and writing. As certain discourses become embedded within particular contexts, they become conventionalized and become recognized, by those familiar with them, as genres serving particular functional purposes. Hence, students need to learn to use the socially appropriate language to convey content through the genres of their discipline. Ballard and Clanchy, in their seminal text on literacy studies, indicate that 'the rules and conventions are nowhere codified or written down, and yet they mediate crucially between the student's own knowledge and intentions, and the knowledge and potential meanings that exist within the university'

$(1988,8)$. They argue that the cultural understandings of the institution and discipline need to be made explicit to students if they are to readily take them on. The cultural understandings refer not only to textual conventions, but also to what counts as knowledge and how knowledge is constructed within the institution and the discipline (Boughey 2002). Knowledge, be it in an educational or other context, is not seen as a unitary, immutable set of facts but rather as differing across time and place and determined largely by the literacy practices of those who construct it.

The power of the 'common sense' status of knowledge construction in the university allows injustices to be hidden. The difficulties students experience in taking on these ways of constructing knowledge can be attributed to some flaw in the student if we, as the university community, do not acknowledge the complex and hidden nature of our ways. The prestigious forms of literacy manifested and expected in the university are presented as neutral and apolitical so interests are concealed (Boughey 2005). These prestigious literacies are unevenly found along the continuum of economic privilege and disempowerment. Our expectations are intricately wrapped up issues of class, as uncomfortable as this may make us feel. This should be taken into account when learners' ways of writing are dismissed by universities as inappropriate.

Morrow (2007, 38) indicates that a primary task of teaching is to enable epistemological access; we need to ensure our students gain access not only to the university itself but also to the ways in which knowledge is constructed in the university. Academic literacy, the practices whereby we construct knowledge, is related to the power and ideological relationships at play within the university and the specific disciplines and departments within it. Academic literacy thus has to do with 'ways of using language but also the beliefs, attitudes and values of the group' (Gee 1990, 146). This identification of the power of the literacy practices of the university does not make them 'bad'. To point out the potential elitism of the common sense understanding of such practices is not to call for the outright rejection of such practices. What this understanding demands is a critique of such practices and a pedagogical engagement with making them accessible to the students wishing to take on these practices as their own.

\section{Research Method}

This research study was located in the Durban University of Technology (DUT) ${ }^{1}$. 
The participants reported on here were twelve students registered on an extended programme; these students were already identified through various entrance tests and their results in the school leaving examination as likely to have difficulty with tertiary study. Of the twelve students, seven were males and fi females. Nine of the students were English Additional language students (one with Greek as her fi language and eight speaking an indigenous African language as their fi language). The remaining three were South Africans of Indian origin who spoke English as their fi language. The students were between eighteen and twenty-three years of age and came from different residential areas and diverse backgrounds.

Multiple data sources were used to ensure as full an understanding of the phenomenon as possible (Cohen, Manion and Morrison 2007). The students completed a questionnaire asking them about their experiences of reading and writing in the curriculum. The questionnaire comprised a mix of open and closed questions and was used primarily to inform the interview process (Terre Blanche, Durrheim and Painter 2007). They were also interviewed to determine their attitudes towards writing and their writing practices including the difficulty they experienced when writing. Each interview session lasted approximately sixty to ninety minutes. The recorded interviews followed a semi-structured pattern allowing the participants flexibility - a process considered by some research theorists (for example, Cohen, Manion and Morrison 2007, Terre Blanche, Durrheim and Painter 2007), as the ideal for qualitative interviews. Each interview was transcribed and coded, looking for patterns of thought and behaviour relating to writing.

\section{Findings and Discussion}

While the data revealed a number of issues related to students' difficulties with academic writing, only four will be discussed in this article. Firstly, that some basic level of proficiency in the medium of instruction seems to be a necessary but not sufficient prerequisite to the acquisition of discipline specific academic literacy. Secondly, that prior school and home literacy experiences can have a major impact on the ease or difficulty students have in mapping the required academic literacy practices. Thirdly, that students were aware of the existence of academic literacy, even if they were vague as to the exact nature of such practices. And fi , that referencing was a particularly complex academic literacy practice which was poorly understood in terms of its knowledge construction functions. Each of these four fi will be discussed in turn.

1This article arises from a broader PhD study (Bharuthram 2007) which consisted of three phases: i) collection of baseline data by questionnaire to ascertain students' and lecturers' attitudes and practices towards writing; ii) interviews around students' writing worlds and practices and iii) an action research component. 


\section{Basic Level of Competency in Medium of Instruction Required}

In the questionnaire, Andiswa ${ }^{2}$ responded to a question probing if they enjoyed assignment writing, as follows: '......Because I now that my English is not good and I am not good in English spell that why I am not like to writ'. Andiswa attained amongst the lowest scores in class assignments. She had great difficulty in expressing herself verbally in English and thus she spoke rarely. On the few occasions that she did speak, it was to answer questions put directly to her. Despite seeming to be relaxed in the interview, she had great difficulty in expressing herself in English. Andiswa also experienced difficulty in writing as can be seen from her written response: 'It is difficult to the essay for me and if I am writing test it is difficulty because of the spell.

I can no what is ask but I will writt as I am talking so that is why it is difficulty for me'. It must be noted that Andiswa failed Grade 12 English and obtained a score of 16/100 in language proficiency pre-test 3 . These 16 marks were obtained for the multiple choice questions, meaning she had a o score for the sentence construction tasks. It could be argued that Andiswa's proficiency in English, the language of instruction at the institution, is so low that she is unable to work at even a basic level and would therefore fi the particular ways of using language within the academy to be virtually impenetrable.

The authors of this article have both been critical of the ways in which academics often conflate students' difficulties in taking on academic literacies with language difficulties (see for example McKenna 2004a, Bharuthram and McKenna 2006), but the findings of this study indicate that without a basic level of competence in the medium of instruction, the student's chance of simultaneously acquiring the requisite academic literacies is nigh impossible. The focus in this article on academic literacy acquisition in no way contradicts the understanding that a certain level of proficiency in the medium of instruction is necessary for success in higher education.

2 For purposes of confidentiality, the names of the participants have been changed.

3 The test used is called the TELP test and is part of the Tertiary Educational Linkage Project which is a United States Agency for International Development (USAID) funded project. The main aim of the test is to identify students who are likely to experience academic difficulties in future situations in which language will be an important, but not the sole, variable. It is based, therefore, on a notion of 'language-as-vehicle rather than language-as-target' (Yeld 2001). 
Volbrecht $(2002,229)$ describes a particular intervention as having the assumption that '...there was a determinate and prerequisite level of entry-level literacy in English, and that students operating below this level would be incapable of attaining acceptable levels of ... academic literacy in the tertiary context'. The need for a basic proficient in the medium of instruction prior to the acquisition of the many literacies required in higher education is thus clearly articulated and the fi of this study proved no different. However, it is almost impossible to reach agreement as to what constitutes sufficient basic fluency in the language of instruction such that a student can be inducted into the ways of using the language required by the university in general and her discipline in particular. It may well be that a very low proficiency in English can be overcome where students already have academic literacy practices in another language.

This conclusion that some students are doomed because of extremely poor language proficiency in the medium of instruction sits uncomfortably with academic developers but seems to be an inevitable one. The data in this study illustrated that students with very low proficiency levels were unable to access even the most surface level meaning of their university learning. To stretch the metaphor of this article's title, these students did not just feel as if the seas they were navigating were uncharted, they felt as if they were being expected to do so without a boat. The inclusion of such students directly into a higher education institution becomes a morally dubious one.

\section{Underprepared for Higher Education}

While the extent to which Andiswa can succeed in taking on strange new literacies when the medium of instruction itself is so difficult for her can be questioned, it should not be suggested that the journey to becoming academic literate was smooth sailing for even the most fluent of the students interviewed. As Bourdieu and Passeron remind us, 'Academic language is no-one's mother tongue' (1977,115). It has been argued elsewhere however (Boughey 2005, De Kadt and Mathonsi 2003) that some home and schooling experiences prepare students better for the peculiar codes of the university while others leave them feeling hopelessly lost.

Given that students enter tertiary institutions from diverse schooling backgrounds, it is crucial to understand the experiences that the students bring with them into higher education. Many of the participants in this study came from schools that are not well resourced and from homes where there was not much exposure to reading material. In particular, fi of the students reported that they had no school or community library, they had no laboratories at their previous schools and their schools suffered a lack of textbooks.

The relationship between reading and writing in terms of constructing knowledge in the academy (Crème and Lea 2003) seemed to be poorly understood by the students interviewed (and possibly also by the lecturers given the practices they seemed to expect of students with little or no mediation as to how other writers construct knowledge in the discipline). It was clear from the interviews that pre-university experiences of writing were restricted almost exclusively to the 
school environment and even there writing was limited to a few, short pieces. Hence, at tertiary level, the sudden exposure to a vast amount of print and projects and assignments in many disciplines resulted in the students reporting feelings of being overwhelmed and bewildered.

The responses of the students in the interviews indicated that even though they acknowledged that they felt 'confused' and were 'struggling', few of them undertook additional work and many did not even complete compulsory written activities. It could be argued that this could stem from their secondary school experiences where they may not have been required to engage with texts independently. Furthermore, it could be the uncertainties and lack of confidence students experience actually demotivates them. Thus, there is a need to make the reading and writing literacy practices in the different disciplines explicit for students, who are not likely to experience a smooth transition into the powerful disciplinary norms.

A critique is also needed of the deficit view of students that arises from a liberal notion that student support is simply about inducting students into the sacrosanct practices of the university. If the teaching practices within higher education are not adapted such that students are overtly inducted into the practices of the institution and taught to bring a critical gaze to such practices, then they can only but revert to the rhetorical reading practices and rote learning of their schooling. An understanding of the harsh realities of many South African students' socio-economic and schooling backgrounds is thus essential but needs to be balanced against serious reflection and critique of the mysterious ways of being demanded of students by the university.

\section{Awareness that there are hidden norms}

The students who were interviewed in this study indicated an awareness that certain practices were being demanded of them for success in their studies. They had difficulty however in articulating this awareness or describing what such practices might be. Pumlani explained in the interview that he had difficulty with the 'formal' nature of academic writing. His difficulties included uncertainty about how to represent the information in his own words and within the 'fixed strategies' he said were expected of him. It seemed that the students experience difficulty particularly in researching information and structuring the assignment in terms of the required linear format, thus indicating that they are not familiar with the literacy rules and conventions of their discipline. Geisler $(1994,211)$ says 'domain content - is not a set of facts simply "found" by the discipline...but is socially constructed by the discipline's members and intimately related to the rhetorical processes underlying the reading and writing of texts'. Generally lecturers at DUT tend to focus only on their discipline content and not on the rhetorical processes used to construct this. They feel that their responsibility is to teach the former; thereafter the latter then will develop automatically (McKenna 2004a). This may not arise out of a stubborn refusal to consider the induction process from the students' perspective; it may well stem from the unconscious nature of such literacy practices. 
The students indicated that they were required to do a fair amount of writing in their disciplines, which involved note taking in the classroom and completing assignments. One of the more overt expectations which the students could articulate in interviews was that of acquiring new terminology as illustrated by the response received from Thembi: 'Yeah, they expect you to use words and your brain doesn't have the information then you go to the dictionary and look up the words or ask people' and Patrick: 'Yes, at times ...there are some terms that are actually in dental technology. We have a dental technology language that when writing you should include things that are done in dental technology and it tends to be more difficult for you to memorize the words you have to use in certain topics. So the difficulty comes when using language terms because we have so many terms we use as dental technicians - that's the problem I have - using the terms the way they want us to use them'.

The students indicated that the writing expectations in assignments were fairly mysterious. As Yasteel explains below, even where she thinks she has demonstrated competence in the discipline concepts her marks reveal that some other issue may be at play, accounting for her disappointing marks: 'When writing assignments I don't experience difficulty. I think I do quite well in that but when the assignment comes back to me I am confused as to why my marks are so low. I don't understand why the marks are so low. All the information is there yet the marks are low'.

Yasteel's comments show that the requirements of the writing tasks are not clear to her. This may be because many of the 'rules and conventions' of the discipline are 'common sense' for the lecturers, making it difficult to foreground such rules and conventions in teaching. McKenna (2004b, 276) argues that because of the subconscious nature of literacies 4 , such as academic literacy, most academics will encounter difficulty in articulating how language functions to establish the norms of their discipline. Even when lecturers are aware that the types of reading, writing and other behaviours expected in higher education involve more than technical language proficiency, they may not necessarily be able to assist their students in acquiring these norms. What may appear to be common sense to the lecturer may present a challenge to the students, as the latter are not able to express how the literacy practices expected of them are strange and difficult to access.

This is illustrated in Patrick's response: 'I always have problem with the way the conclusion has to be arranged and more problem comes from lack of information'. Patrick wrote very little at school and his experience of writing conclusions was limited to those required at the end of an 'English story' at school. In the Dental Technology reports he is expected to write at university, the conclusion has a very different structure, content and style underpinned by a very different set of values and attitudes. Ballard and Clanchy (1988) indicate that the rules and conventions that define the construction of knowledge have to be understood because the texts, which embody an institution's knowledge, do so within these rules and conventions. The problems that Patrick experiences became clearly evident in the extended action research component of the study where he needed additional attention in terms of explanations of the different tasks, but he still struggled to keep up with the rest of the students. A serious problem encountered when responding to Patrick's draft 
assignments were his constant use of 'difficult words, which were almost always used incorrectly. However, Patrick's attempt to use sophisticated vocabulary does suggest a real motivation to engage with the task and his awareness that there are academic discourse requirements that would give his assignments the credibility, authority and integrity so valued by the academy. His incorrect use of difficult vocabulary is no doubt evidence of his awareness that an elevated discourse is required. Sadly, this awareness was no assistance in acquiring the exact literacy practices expected of him.

4Because of the emphasis in literacy studies on the specificity and shifting nature of social, cultural and political contexts, it is common to refer to literacies rather than literacy. 
Patrick battled to distinguish between what the discipline considers relevant and irrelevant information for his assignments as is evident when he said: 'I always struggle to know what to put in my assignments....'. In a similar vein, Melanie said: 'Sometimes I carry on explaining until I go way out of the subject and in the end I get confused and forget what I really wanted to explain'. Although Melanie's use of the English language was much more coherent than Patrick's, she also often experienced difficulty in extracting the relevant information required for an assignment task. One way in which students can be assisted in deciphering relevant from irrelevant information is through the explicit teaching of how other authors have included or excluded issues in their writing. Again though, without an understanding of the values of the discipline and what the discipline is doing when it constructs knowledge in certain ways, all such teaching runs the risk of being a set of technical and flawed instructions.

When the students were asked about the guidelines they were given for their assignments, the students were divided in their responses: eight students said they received no guidelines beyond the assignment topic, while one said 'sometimes', and another was 'not sure', and only two students indicated that they were clearly informed of the assessment criteria. Some responses include those of Thembi: 'They do, they tell you if you use text how to reference it... They tell you the basic stuff and the rest is how you make it interesting' and Lunga: 'Not at all. You see we have this learner guide so lecturers just refer us to the learner guide. Ya, but in the learner guide there is everything'.

The learner guide that Lunga mentions provided general technical information on the assignments i.e. it had to be typed, information on font size, line spacing, and so forth. There was no mention of the more elusive kinds of norms expected of students, nor any indication that the values and attitudes of the discipline were at the heart of such norms. This is not surprising since such engagement would be difficult to include in a learner guide. In the interviews, there was an attempt to garner examples of where the discipline specific writing expected of them may have been discussed and scaffolded in other formats. However, the students were unable to recall instances where lecturers provided details of how an assignment should be structured or provided examples of assignments for discussion. Given that the students interviewed were undertaking an extended curriculum because of concerns about their ability to cope with higher education, such input could be seen as an essential tool for them to map out the kinds of writing expected of them.

The students all indicated awareness that there were specific writing expectations in higher education which were different from writing they may have done at school or elsewhere. There was even some understanding that these expectations were tied to the particular discipline they were studying. However, the students were less able to articulate what these expectations were or how the students could meet them. Only one particular academic writing norm was directly and repeatedly referred to and that was the norm of citing other texts.

\section{Referencing as a particularly difficult writing practice}

The students experienced major difficulties with referencing in their 
assignment writing, as typified by Lunga's response: 'I think its because I have to be accurate, have to follow rules for example for referencing'. The problems that students experience with referencing are not particular to the students interviewed in this study; they have been discussed by many researchers (for example, Angélil-Carter 2000; and Hendricks and Quinn 2000 have looked at this within a South African context). Angelil-Carter (2000) argues that referencing is not a technical skill but is fundamental to an understanding of how knowledge is constructed and contested. This point is echoed by Hendricks and Quinn (2000, 448) who state that being able to integrate one's own ideas with the ideas of others from various sources is the key to knowledge construction in the writing of academic essays.

Many lecturers do not teach their students how to reference or, more importantly, why and when to reference, because it is seen as something that should have been learnt in school or in add-on academic skills programmes. In instances where referencing is mentioned, it is usually explained as a way of avoiding plagiarism rather than as a way of giving greater authority to one's statement or as a way of supporting evidence. Hence, many students do not see the value of referencing and they merely include references in their assignments to satisfy their lecturers.

There have been many calls for the explicit teaching of academic literacy practices such as referencing within each discipline (for example Lillis 2003 and Haggis 2003). In a study conducted by Hendricks and Quinn $(2000,455)$ it was found that after the explicit teaching of referencing in an integrated manner, students were successful in using the technical conventions of referencing.

However, students continued to experience 'problems understanding the readings and integrating a quote or idea into their own writing'. Hendricks and Quinn (2000, 456) believe this is so because 'students, at this stage, are novices in terms of their development of academic literacy and their understanding of epistemology'.

The academic norm of using other people's voices within their own writing in ways that did not subsume their own voice was extremely difficult for these students. A number of them have a limited English vocabulary and therefore they are more likely to experience difficulty in understanding discipline readings as well as integrating the ideas of others with their own. For example, Edna stated: 'I hate writing assignments because I have to write the assignment in my own words and if I have to copy it out I have to reference it, I think that's too much for me. When I write in my own words I make lots mistakes'. Many students expressed difficulties in using the particular voice expected by the academy.

The students in this study admitted to avoiding using their own words and often resorting to plagiarism. A major factor for many students seems to be a lack of confidence in using their own words. They realise that using their own words may result not only in grammatical errors, as indicated by Edna earlier, but that they may use the 'incorrect' voice as determined by the academy. This issue arose a number of times in this study. 
Students can increase their vocabulary by reading widely, but they need to be reading the 'right' kind of texts in the ways expected by the discipline. However, given the socio-economic situation of many students and their lack of experience in the kinds of reading expected of them the objective of reading to improve vocabulary becomes difficult to realise. Furthermore, readers who experience difficulty in reading are reluctant readers even when material is available and they may have learnt to set aside the written word in favour of other ways of knowing. For example, when Vilakazi was asked if he read the prescribed textbooks he stated: 'I find it difficult. It is easier to read a novel than a text book'. On probing further as to the novel he last read he added "I read at school. Now I only read for when I'm doing an assignment. I prefer the TV'. Reading at university may need to be mediated for these students to point out the ways in which the academic voice is used. Being told to use third person only because it is the "proper way of writing" is far less helpful than a class discussion around how the use of third person signals the kind of objective distancing valued by that discipline.

\section{Conclusion}

This study investigated the attitudes and practices of writing of a select group of students at a higher education institution in South Africa in an attempt to identify the writing difficulties that they experienced. The interviews with the students indicated a lack of familiarity with the literacy norms and conventions of their discipline. This hindered their ability to structure their written assignments, select what information to include and how to use the literature appropriately. It was also found that not enough space was provided within the curriculum for engaging with the norms and conventions of the disciplines, nor was there sufficient scaffolding of their acquisition of the target practices. Given that these students had been initially identified as being at risk in the university, the need for such support is crucial. 


\section{References}

Angelil-Carter, S. 2000. Stolen language?: Plagiarism in writing London: Longman

Ballard, B and J. Clanchy. 1988. Literacy in the university: An 'Anthropological' approach. In Literacy by degrees, ed. G. Taylor, B. Ballard, V. Bock, J. Clanchy, and P. Nightingale, 7-23. Milton Keynes, SRHE.

Bharuthram, S. 2007. Developing reading strategies in higher education through the use of integrated reading/writing activities: A study at a University of Technology in South Africa. Unpublished PhD dissertation. KwaZulu-Natal:Durban.

Bharuthram, S; and S. McKenna. 2006. Writer Respondent Intervention as a means of developing Academic Literacy. Teaching in Higher Education 11(4): 495507 .

Boughey, C. 2002. Naming students' problems: an analysis of language-related discourses at a South African university. Teaching in Higher Education 7(3): 295307.

Boughey, C. 2005. Epistemological access to the university: An alternative perspective. South African Journal of Higher Education 19(3): 230-242.

Boughey, C. 2007. Marrying equity and efficiency: The need for third generation academic development. Perspectives in Education 25(3): 27-38.

Bourdieu, P. and J. Passeron. 1977. Reproduction in education, society and culture. Beverley Hills, CA: Sage.

Cohen, L; Manion, L; and Morrison, K. 2007. Research methods in education. 6th Edition. London: Routledge.

Crème, P; and M. R. Lea. 2003. Writing at university: A guide for students. UK: Open University Press.

De Kadt, E; and N. Mathonsi. 2003. Writing in English with an 'African voice': Ownership, identity and learning. Journal of Language in Teaching 37(1): 92-103.

Gee, J. 1990. Social linguistics and literacies: Ideology and discourse. London: Falmer Press.

Geisler, C. 1994. Academic literacy and the nature of expertise. Hillside, NJ, Lawrence Erlbaum.

Haggis, T. 2003 'Constructing Image of Ourselves? A Critical Investigation into “Approaches to Learning” Research in Higher Education. British Educational 
Research Journal 29(1): 89-104.

Hendricks, M. and L. Quinn, L. 2000. Teaching referencing as an introduction to epistemological empowerment. Teaching in Higher Education. 5(4): 447-457.

Lillis, T. 2003. 'Student writing as “Academic Literacies": Drawing on Bakhtin to move from critique to design'. Language and Education 17(3): 192-207. McKenna, S. 2004a. Lecturers' discourses about the interplay between language and learning. South African Journal of Higher Education 18(2):278-287.

McKenna, S. 2004b. The intersection between academic literacies and student identities. South African Journal of Higher Education 18(3): 269-280.

Morrow, W. 2007. Learning to teach in South Africa. Cape Town: HSRC Press. Scott, I., N. Yeld and J. Hendry. 2007. A case for improving teaching and learning in South African Higher Education. Higher Education Monitor Series: 6. Council on Higher Education: Pretoria.

Terre Blanche, M., Durrheim, K., and D. Painter. 2007. Research in practice: Applied methods for the Social Sciences 2nd Edition. Cape Town: UCT Press

Volbrecht, T. 2002. Plot and practice: A narrative inquiry into academic development, language policy and lifelong learning as frameworks for literacy development at the University of the Western Cape. D. Litt. Thesis.University of the Western Cape, Bellville.

Yeld, N. 2001. Report on the development of Version 4 of the placement test in academic literacy (English), The Desmond Tutu Educational Trust. 